\title{
THE NEIGHBORHOOD: A STUDY OF LOCAL LIFE IN THE CITY OF COLUMBUS, OHIO-Concluded
}

\author{
R. D. McKENZIE \\ University of Washington
}

\begin{abstract}
Our system of government is based upon the assumption of the territorial group as a unit. Modern means of communication and transportation have to a considerable extent nullified the significance of spatial proximity as a group bond. All the traditional forms of political and social organization are affected thereby. Wards and administrative districts of cities as a rule have no correlation with natural groupings of population. Thus the influence of local opinion in social control is minimized. City populations tend to segregate into territorial publics having similar attitudes on questions pertaining to the mores. Such similarity of attitude is not so pronounced on economic questions. Rehabilitation of neighborhood sentiment in a city is a difficult problem. Anything that tends to stabilize residence and give to the neighborhood a unitary character may serve to develop neighborhood consciousness.
\end{abstract}

\section{PART III. SOCIAL RECONSTRUCTION OF THE NEIGHBORHOOD}

XIII. THE NEIGHBORHOOD AS THE UNIT OF POLITICAL AND

\section{SOCIAL REFORM}

Our entire system of government, municipal, state, and national, is based on the assumption of the locality group as the unit of representation and administration. This, of course, is an inheritance from earlier times when geographical proximity was the one fundamental basis of group life. But modern means of communication and transportation together with the recent development of large interest groups whose common interest transcends geographical boundaries have undermined the foundations of our political system and have complicated all our problems of social reform. This is especially true with reference to affairs of administration in our large cities, where the dominant interest groups prevail and where life for the majority is precarious and transitory.

Localities do not stand for special interests, being areas of community which circumscribe only a very limited and, with the extension of community, less and less definite exclusiveness of social type and interest. It is in very great measure the mere convenience of contiguity rather than the intrinsic 
distinctiveness of local interests which makes the locality an effective social unit. But in the central association that convenience no longer counts, and here organization by local divisions is, except under special circumstances, a mere impediment to the activity of the association. The case of representative government has interest in this connection. While the unit of election remains locality, the division of interest within the central legislature scarcely ever follows the lines of locality. Consequently it becomes very difficult to attain any form of true representation on the basis of local election. Members ostensibly elected to represent a locality, often in fact represent, though inadequately on account of the mode of election, not merely the broad policy of a party, but the special interest of some association, some trade or profession or church or other grouping. This cross representation is creating one of the most difficult problems within the sphere of political science. ${ }^{x}$

In general the criticisms of our city government, as far as they pertain to the neighborhood, may be divided into two classes. First, the excessive localism revealed by some of the more stable and stronger city neighborhoods tends to exploit the larger interests of the city in general. This type of situation is illustrated in the following quotation from the Pittsburgh Survey.

It is not suprising, therefore, that Pittsburgh early became a hotbed of petty politics. As in other cities councilmen chosen by wards throve through catering to local needs while indifferent or negligent to the weightier interests of the city as a whole. Thus, whole sections of well-paved streets might mark the bailiwick of some aggressive ward councilman, who none the less had a hand in giving these same streets along with the main thorofares of Pittsburgh, in perpetuity to the street car monopoly. Hence the saying: "Any ward can be bought for a new side walk or a pair of wooden stairs." Local benefit naturally became the test of discharge of official duty, the street paving schedule, the pork barrel of the city budget. . . . . Even justice has been so diverse an interest that each ward chooses its own local magistrate, before whom, none the less, may be brought a case from anywhere in the city. The only concern of an alderman is to please his "constits"; let him "soak" the fellow outside his district and his re-election was secure. ${ }^{2}$

On the other hand, the utter lack of neighborhood sentiment, so common in many sections of our large cities, provides a fruitful field for the establishment of our notorious boss system of government. The boss seizes upon the opportunity to act the part of the good neighbor among an element of the population whose precari-

${ }^{2}$ R. M. Maciver, Community (1917), p. 258.

2 Pittsburgh Survey, I, 45-46. 
ous conditions of life emphasize the value of the kindly, personal, neighborly relations, but at the same time create indifference toward the more general interests of the neighborhood or community as a whole.

A successful ward boss must be a worker, capable by his example of inspiring others to similar industry. He must not be content with doing the work that comes to him, he must look for things to do. As his work consists mainly in doing favors for voters, he must inspire requests as well as grant them. Therefore he encourages voters to come to him for help when they are out of work or in any other sort of trouble. When a voter is arrested, the ward or district leader will lend his services to secure bail or to provide counsel, or will arrange to have the offender's fine paid for him. Then there are the day-to-day favors which the local boss stands ready to do for all who come to him, provided they are voters or can influence voters. These services cannot be even recapitulated here, for their name is legion. To one he lends money to stall a landlord whose patience is exhausted; to a family of another he sends fuel or provisions in time of need. "He buys medicine for the sick and helps to bury the dead. He dispenses an ample hospitality in the saloons; as soon as he comes in, known and unknown, gather about him, and he treats everybody. $\mathrm{He}$ is the only one who does not drink, for he is on duty." Tested by his acts, the boss is chief among neighborhood philanthropists; judged by the motives that prompt his acts, he is a serpent spreading the slime of political debauchery over whole sections of the community. With the submerged tenth (it would be more accurately termed the submerged half) of a great city's population, however, it is the acts and not the motives of the man that weigh. ${ }^{\mathrm{x}}$

Students of municipal affairs disagree concerning plans for the reconstruction of city government. Some authorities, recognizing the present disorganized state of the city neighborhood, advocate the selection of representatives at large without respect to neighborhood or vocational interests; ${ }^{2}$ others would even go so far as to abolish entirely the geographical unit of representation and substitute for it representation on the basis of vocational or interest groups; ${ }^{3}$ while others again, realizing the importance of neighborhood sentiment as a civic force, would attempt to rehabilitate and revivify the neighborhood making it function once more as a

${ }^{2}$ Munro, The Government of American Cities, pp. 175-76.

${ }^{2}$ This is the position taken by exponents of commission government. Cf. E. S. Bradford, Commission Government in American Cities (IgII), p. 305.

3 For a concise statement of the views of the "Political Pluralists" see M. P. Follett, The Nerw State (1920), chap. xxviii. 
community institution. ${ }^{\mathbf{x}}$ There is general agreement, however, that our present ward system of representation is a failure.

The ward councillor represents his own ward, and that alone. He forgets that the city is more than the sum of its wards, and that the public opinion of the city may be different from the totality of neighborhood clamors. Ward divisions are at best ephemeral: unlike the French arrondissement, the American ward has rarely any traditions and as a unit of area exacts no spontaneous loyalty from the people who live in it. What passes for ward loyalty is, more commonly than not, local prejudice fostered by politicians to serve their own personal ends. Moreover, the concentration of single ethnic elements in particular sections of the city makes it practically certain that, under the ward system, some members of the council will owe their election to nothing but their proficiency in appealing to racial or religious or social narrowness. The ward system likewise affords a standing incentive to that most vicious of all American contributions to the science of practical politics, the gerrymander; it makes possible the control of a majority in the council by a minority of the city's voters, and, unless redistricting is resorted to frequently, it fosters gross inequalities in representation. The term "ward" has accordingly come into disrepute in the terminology of American government, a somewhat curious fact, by the way, since in England, where councillors are and always have been chosen from wards, no such odium has been developed. Its presence here is doubtless explained by the fact that in American ward representation, ward politics, and ward organization have come to be associated in the public mind with bossism, trickery, and almost everything else that is politically demoralizing. A feeling so deeply lodged can scarcely be without some substantial foundation. ${ }^{2}$

Although the territorial unit of representation is tending to become a thing of the past in American city government, yet the unit for administrative purposes still remains the geographical area. Cities are districted into a large number of local units to meet the

${ }^{x}$ M. P. Follett is one of the best-known advocates of the rehabilitation of the neighborhood as a political and social unit. The thesis of her recent book, The New State, is that intelligent participation in social control can be achieved only through the conscious reconstruction and federation of such small territorial groups as the neighborhood.

As a unit of social reform, the neighborhood has received the attention of social workers for several decades. The social settlement movement represents the first attempt to institutionalize the social activities of the neighborhood. The present trend of this movement is evidenced in the increasing popularity of the social center activities, community councils, and, in a still more comprehensive way, in the social Unit Plan of Cincinnati.

${ }^{2}$ Munro, The Government of American Cities, pp. 191-92. 
administrative problems of the various departments of city government. Each department subdivides the city into geographical units adjusted to suit its peculiar administrative purposes without respect to the natural groupings of population, and without consideration of the geographical subdivisions made by other departments of city government.

Attention has been called to the fact that one of the things which make city government inherently difficult, is the lack of neighborhood feeling which seems invariably to be produced by city life. If each branch of the city government, and each city executive department, forms districts to suit its own convenience merely, it is almost a certainty that there will be almost as many series of different districts as there are branches of city government and city executive departments. The result is that such a neighborhood feeling as may exist is disintegrated, and that it becomes impossible, so long as this administrative diversity continues, for such a neighborhood feeling to develop. If, on the other hand, care were taken to make the election districts the same as the judicial districts and to cause these to conform, in some way, to the police, fire, and other districts; if the district court-house, the fire engine-house, the police station-house, and even the school-house in given parts of the city were situated, from the point of view of city geography, near each other-placed perhaps in or around a small playground or park,-it would be possible to develop civic centers which would tend to encourage the development of neighborhood spirit. It is quite true that the convenience of the departments might be interfered with, but the loss suffered by the departments would be more than compensated for by the development of neighborhood spirit, and in many instances as well by the greater convenience of the citizen who would find that his business with the city government could be conducted with greater ease than under conditions where the city districts bore no relation to each other. Under the plan which has been outlined, of course the districts would be more permanent than at present, while the civic centers which might develop would, of necessity, be absolutely permanent. The changes of population which are going on so continuously in the city would make the problem of district representation a different one from what it is where the districts are not permanent but are changed to suit the changes of population. The problem would not, however, be one of great difficulty, for, instead of establishing single districts as at present, it would be possible to make provision for districts whose representation would vary with their population.

The plan which has been outlined is one which to a large degree has been adopted in Paris. Paris is divided into twenty districts, each of which has a civic center-the mairie - at which are found the office of the maire, in this case a district and not a city officer-generally a city library, and the local office of 
the charities department. The mairie itself is usually situated in a small open space or park. The twenty districts, in addition to being thus administrative districts, are also election and judicial districts. In this case, notwithstanding their differences in population, they are equally represented on the city council. So far, however, in the United States little attention seems to have been given by the city governments to this important matter, and the convenience of the administrative departments alone has been considered. The result is that an opportunity has not been availed of either to preserve or to develop neighborhood feeling, or to secure an architectural effect which would render city life much more attractive than it is at present. ${ }^{x}$

If the neighborhood is ever to be organized as a political or social unit, it is of the utmost importance that the formal superstructure shall be made to coincide as nearly as possible with the natural neighborhood groupings of the population. It is a remarkable fact that the most prominent advocates of neighborhood reconstruction have failed to take cognizance of this necessity. It is surely apparent that any effective system of community planning must take account of the divergent attitudes of the various community groups; and this is just as important with respect to the locality groups as it is with respect to the trade union or chamber of commerce.

It is, of course, not always an easy problem to locate the boundaries of natural neighborhood groups. Frequently one neighborhood blends into another without any objective signs of demarcation. On the other hand, areas of similar objective characteristics may be inhabitated by family groups whose interests and attitudes are entirely irreconcilable.

I shall now present the results of an attempt to study neighborhood group attitudes in the city of Columbus. My study is based on data obtained from the records of the Board of Elections. The geographical units for the collecting and recording of data on all subjects on which the city's electorate votes are the precincts and wards. Columbus is divided into sixteen wards having a total of 262 precincts. The precinct is quite small, including but one or two city blocks and having an average registered electorate of less than two hundred.

× Frank J. Goodnow, City Government in the United States (r9o6), pp. 20I-3. 
I shall attempt to discover the territorial distribution of the voting public ${ }^{x}$ son a number of issues which have come before the electorate during the past few years. Municipal questions divide the voting public into two groups - those in favor and those opposed. After a campaign which varies in intensity according to the nature of the issue, a vote is taken and the result apparently accepted by both sides. The geographical distribution of the losing minority seems of little consequence. From the standpoint of law enforcement, however, it becomes a very significant matter whether one city neighborhood has imposed its will on a numerically smaller neighborhood entirely out of sympathy with the decision. Without the support of the local opinion of the neighborhood it becomes extremely difficult to enforce legislative enactments. If, on the other hand, the losing minority does not happen to be segregated in particular neighborhoods, but is scattered evenly throughout the city, the question of law enforcement is of a much more simple nature.

In order to ascertain the types of municipal questions on which local segregation of voters takes place, I have made a study of the voting records on eight different issues on which the electorate of Columbus have voted during the past few years. The percentage of affirmative votes on each of the eight municipal questions recorded in Table XXV has been determined for each ward. The results are compared with the percentage of the affirmative votes on each issue for the city as a whole. The deviations of each ward from the city's average is thus taken as a measure of the ward segregation of voters on each question.

This table shows very distinctly that there is much greater segregation of voters on subjects pertaining to the mores, or social customs, than on subjects which deal with economic questions. In the first group of subjects, designated Class A, the ward deviations from the city's average range from 6 to i 2 - a fact which shows that there is a very pronounced local bunching of similar attitudes on

Iny unorganized association of individuals bound together by common opinions, sentiments, or desires and too numerous for each to maintain personal relations with the others, constitutes a public in the broadest sense of the term."-W. J. Shepard, "Public Opinion," Amer. Jour. of Sociol., XV, 36 . 


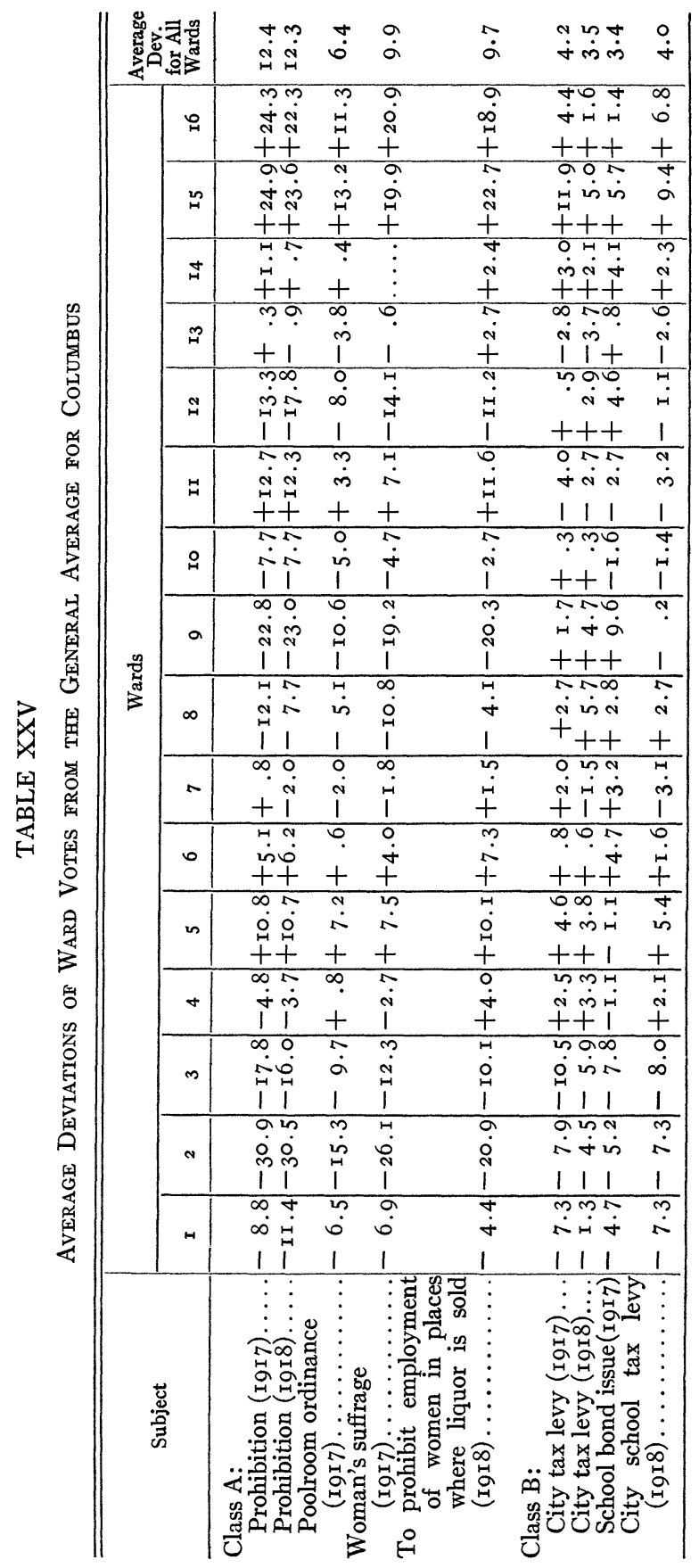

This content downloaded from 184.003.242.175 on March 01, 2018 22:41:59 PM All use subject to University of Chicago Press Terms and Conditions (http://www.journals.uchicago.edu/t-and-c). 
these questions. Wards $I_{5}$ and 16 , which show the highest positive deviations, stand in striking contrast to Wards 2, 3, and 9, which show almost as large negative deviations from the average for the city as a whole. With respect to the economic issues, grouped in Class B, the ward deviations from the city's average are relatively slight. On no subject is the average deviation for all the wards in Class B as great as that found for any of the issues in Class A. The most conspicuous bunching of opposites is found in Wards 3 and I5, especially on the city tax levy issue of I9I7.

Although small deviations are found on the School Bond issue of I9I7, nevertheless, from the standpoint of community interest and campaign enthusiasm, this was an unusually hotly contested local issue. The two publics concerned, however, were geographically dispersed almost uniformly over the entire city. Athough the final vote stood 9,738 for, to 22,918 against, not a single precinct in the city voted a majority in favor of the proposed bond issue.

There seems to be little correlation between high economic status and the tendency to support measures involving an increase in taxation. While Wards 4 and 5 rank highest in the city with respect to economic status, still, on the average, they do not support economic measures as well as Ward 9 which stands at the bottom of the economic scale for the city. Furthermore, it is interesting to note that the deviations of Wards I, 2, and 3, wards which comprise the large German neighborhood, are negative on all questions listed in our table; while the deviations in Wards 14,15 , and 16 are positive on all issues. Wards 9 and $10^{x}$ have negative deviations on all issues in Class A but tend to support taxation measures. This may be partially accounted for by the relatively small number of large taxpayers in these wards.

Let us now examine more closely the territorial distribution of the publics supporting and opposing each of the foregoing subjects grouped in Class A, as representing the mores, that is, questions involving conceptions of right and wrong. Of course the ward is too large a geographical unit to furnish a true picture of the details of local sentiment on these subjects. Local groups of diametrically opposite points of view are frequently bunched together within the

× These wards embrace the disorganized neighborhood already studied. 
same ward. The precinct, therefore, is a better unit than the ward, to bring into relief the natural boundaries of the local group. In order to illustrate the various regional attitudes on questions pertaining to the mores I have prepared Maps XIV, XV, and XVI.

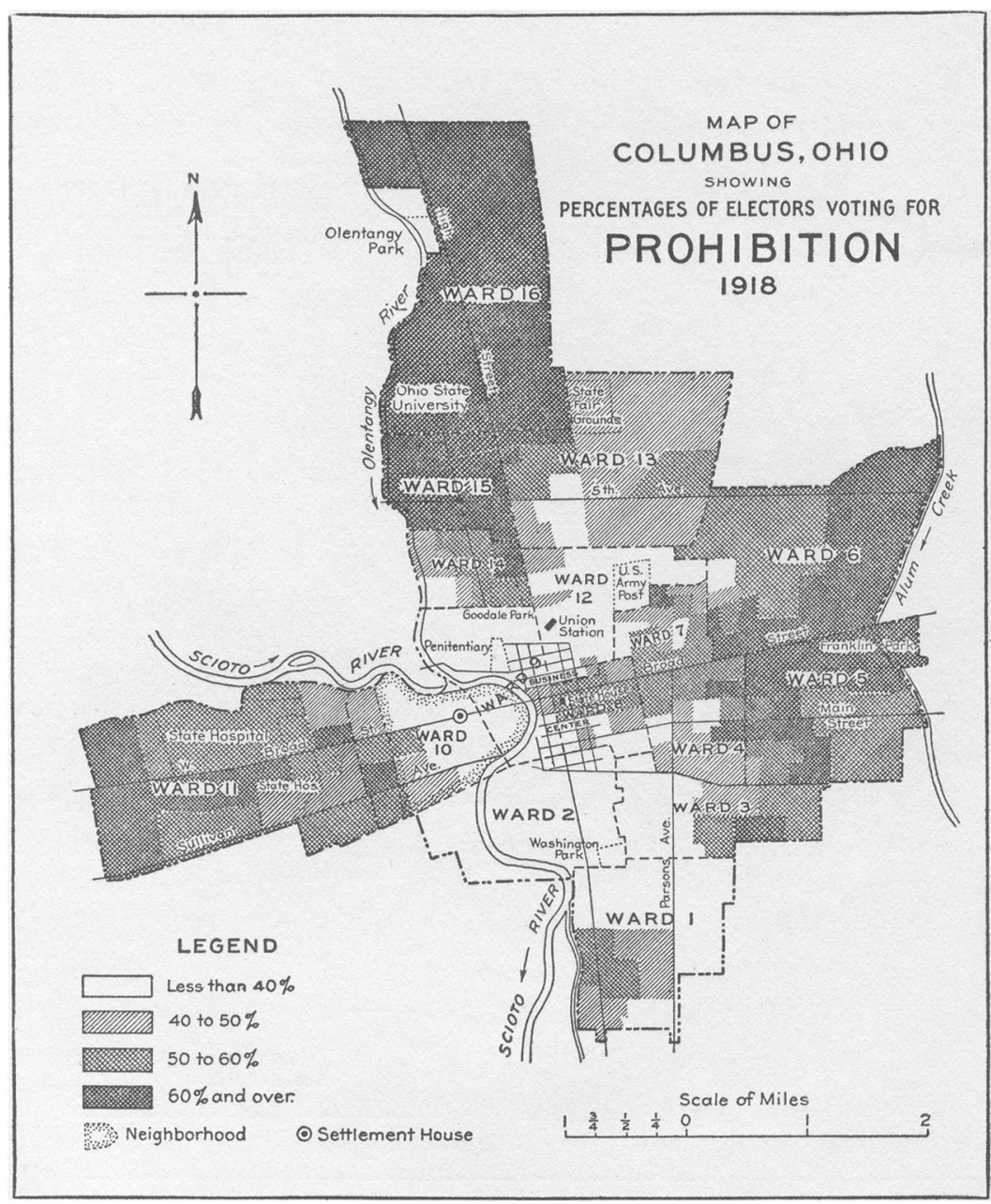

MaP XIV

These maps are constructed on the basis of the voting precinct and represent the percentage of electors for each precinct voting affirma- 
tively on the three subjects in question-prohibition, woman's suffrage, and the non-employment of women in liquor shops.

The similarity of shading of the various sections of the city in all three of these maps is significant. The local areas that supported

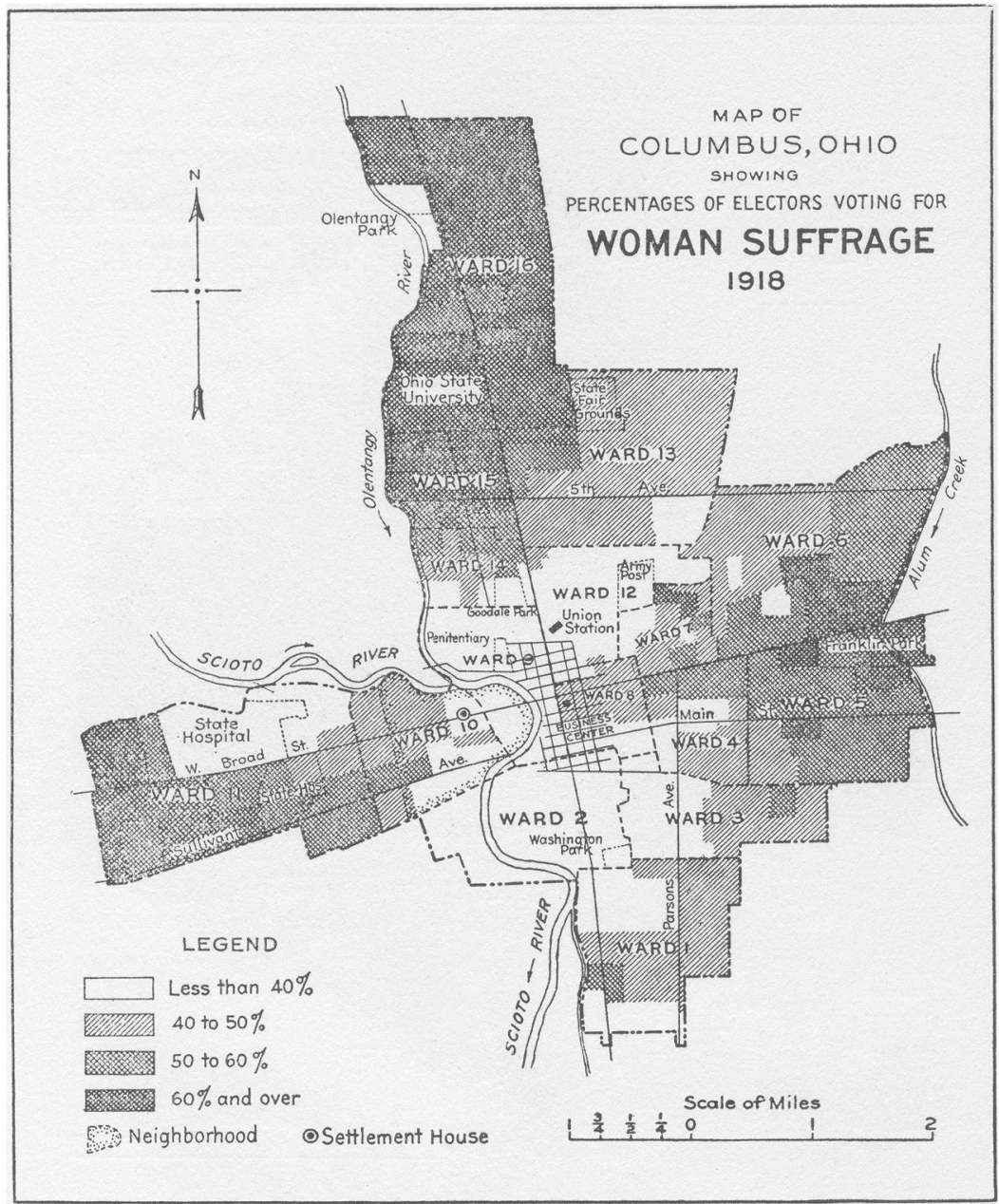

MAP XV

prohibition invariably supported woman's suffrage to approximately the same degree. The areas surrounding the central business section of the city stand out conspicuously as opposed to both 
prohibition and woman's suffrage and in favor of the employment of women in liquor shops; while the eastern, western, and northern extremities of the city-the three leading residential areas-are

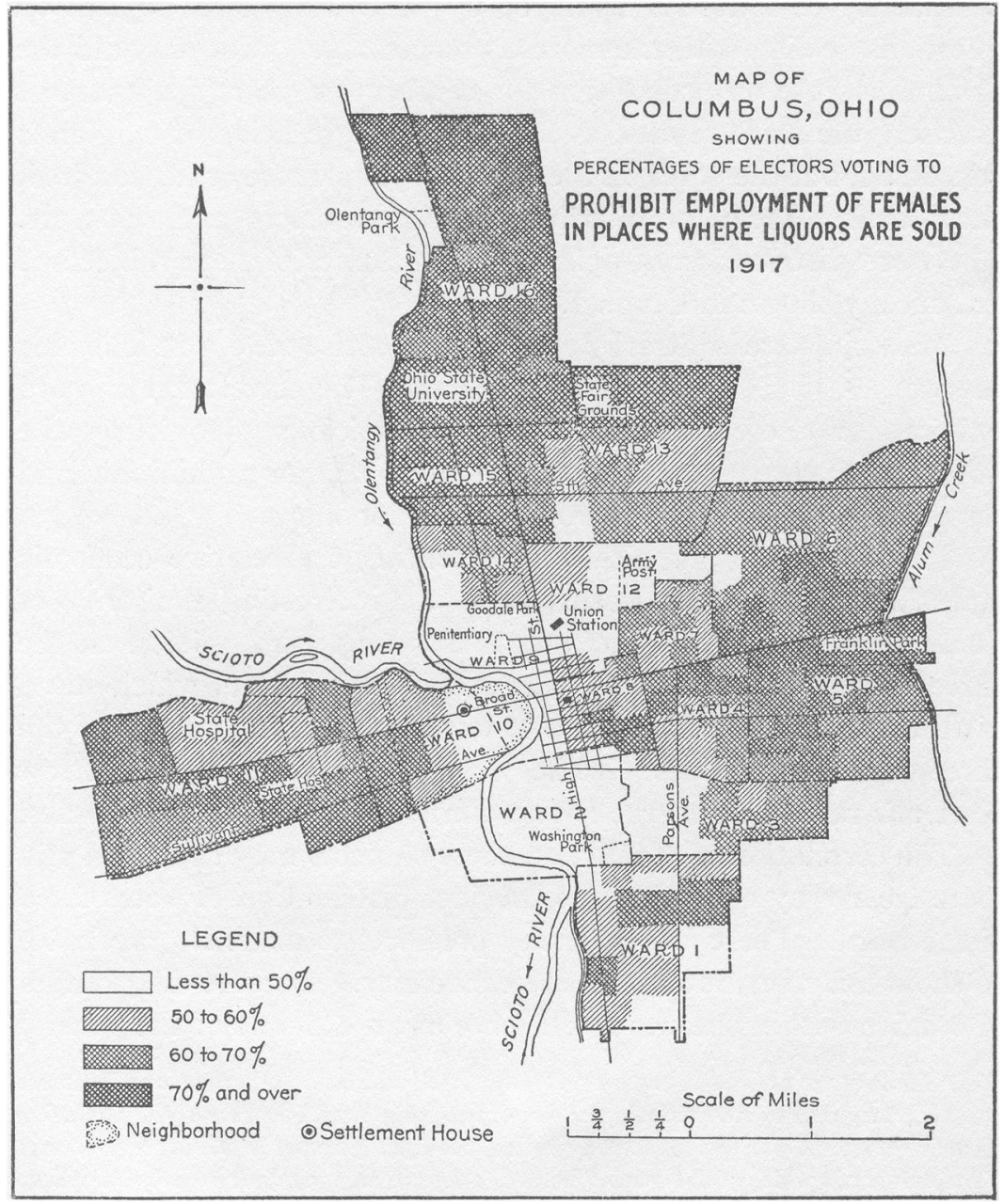

MAP XVI

strong supporters of the first two issues and opposers of the third issue.

In the process of the sifting and sorting of population within a city, there is a tendency for people of similar mores to become 
grouped together in neighborhood association. ${ }^{x}$ And it is only in the decision of questions involving the mores that the specific group character of these local areas comes into prominence. The consistency of attitudes displayed by the various local regions on questions dealing with the mores is remarkable. Not only did the Columbus vote on prohibition for consecutive years show almost precisely the same results, as far as local segregation of opinion is concerned, but the votes on the other subjects, more or less kindred, show almost identical distribution of supporters and opposers. The ward distribution of opinion on a number of such subjects is graphically shown in Graph I.

The points are arbitrarily connected to assist the eye in following the ward fluctuations on these subjects. The correlation of ward opinions on these three subjects is conspicious. Obviously the voter who favored woman's suffrage voted also for prohibition, and for the non-employment of women in liquor shops.

The lower line graphically representing the relative economic status of the different wards, bears an interesting similarity of fluctuations to those of the lines illustrating ward opinion on the three subjects in question. Wards 4,5, I $_{5}$, and I6, which stand high in economic status are the strongest supporters of each of the three municipal issues; while Ward 9, which has the lowest economic rating, shows the lowest affirmative vote on these issues.

The correlation of opinion on these subjects may be shown still more clearly by observing the precinct distribution of votes for a single ward. There are too many precincts to make it practicable to show this distribution for the entire city. But the distribution of opinion within one ward will serve as an example of the general

I Similarity of attitudes, however, is not in itself a criterion of group consciousness. It is necessary that the individual members of the group shall be aware of the similarity of their attitudes. Referring to the Polish peasant, Thomas and Znaniecki, say, "The manner in which social opinion holds the community together is easily analyzed. Any extraordinary occurrence becomes for a certain time the focus of attention of all the members of the community, an identical attitude toward this is developed, and each member of the community is conscious that he shares the general attitude or that his attitude is shared by the rest of the community. These are the three original elements of the mechanism of social opinion: the phenomenon, the identity of attitude, and the consciousness of this identity."-The Polish Peasant in Europe and America, I, I45. 

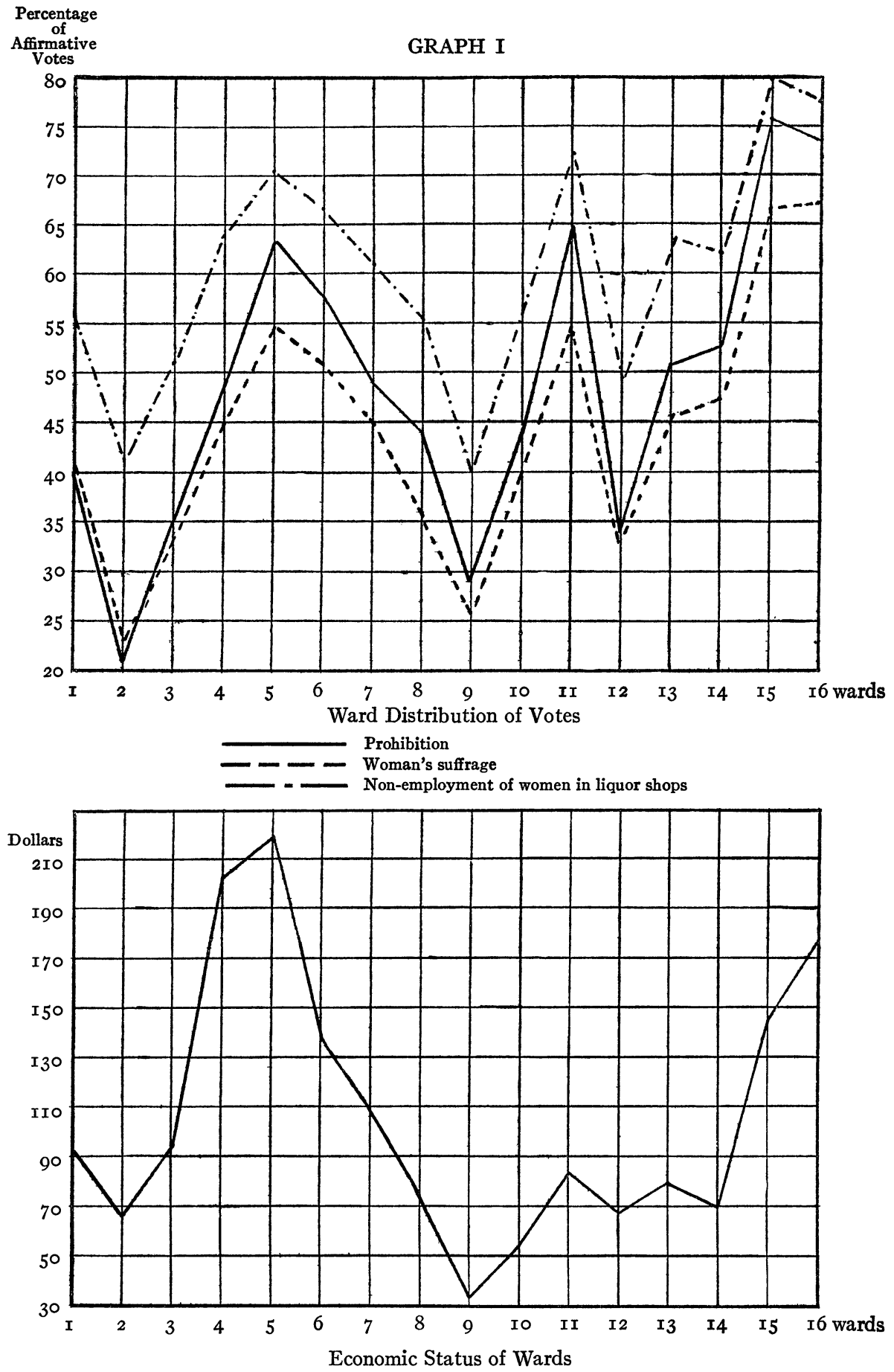

NotE.-Economic status is determined by dividing total tax returns, per ward, on household furniture by total number of electors per ward.

This content downloaded from 184.003.242.175 on March 01, 2018 22:41:59 PM

All use subject to University of Chicago Press Terms and Conditions (http://www.journals.uchicago.edu/t-and-c). 
tendency. Graph II indicates the percentage of voters in each precinct in Ward 3, who voted in favor of the three issues: woman's suffrage, prohibition, and the non-employment of women in places where liquor is sold.

While the percentages of affirmative votes do not fluctuate similarly in every case still it is very plain that there is a direct GRAPH II

Precinct Distribution of Votes on Three Issues-Ward 3

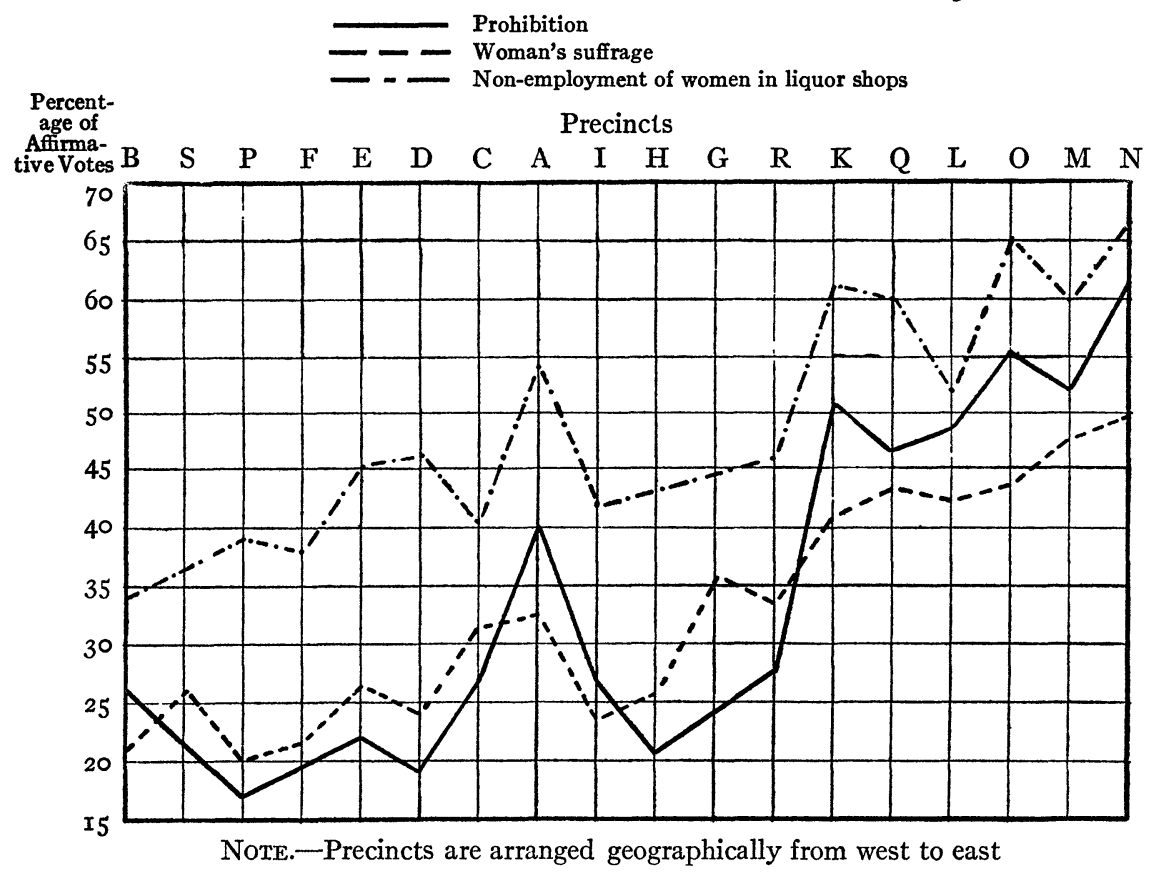

correlation of opinion on these three issues. Moreover, it is evident that there is a decided regional divergence of opinion within the boundaries of this ward. Precincts $\mathrm{M}, \mathrm{N}$, and $\mathrm{O}$, which lie in the eastern end of the ward, represent opposite attitudes to those of such precincts as $B$ and $S$, which occupy the western section of the ward, bordering on Sixth Street.

It is clear to everyone that ward boundaries, as a rule, are purely artificial, and do not, therefore, represent the natural groupings of population within a city. However, all wards in Columbus are 


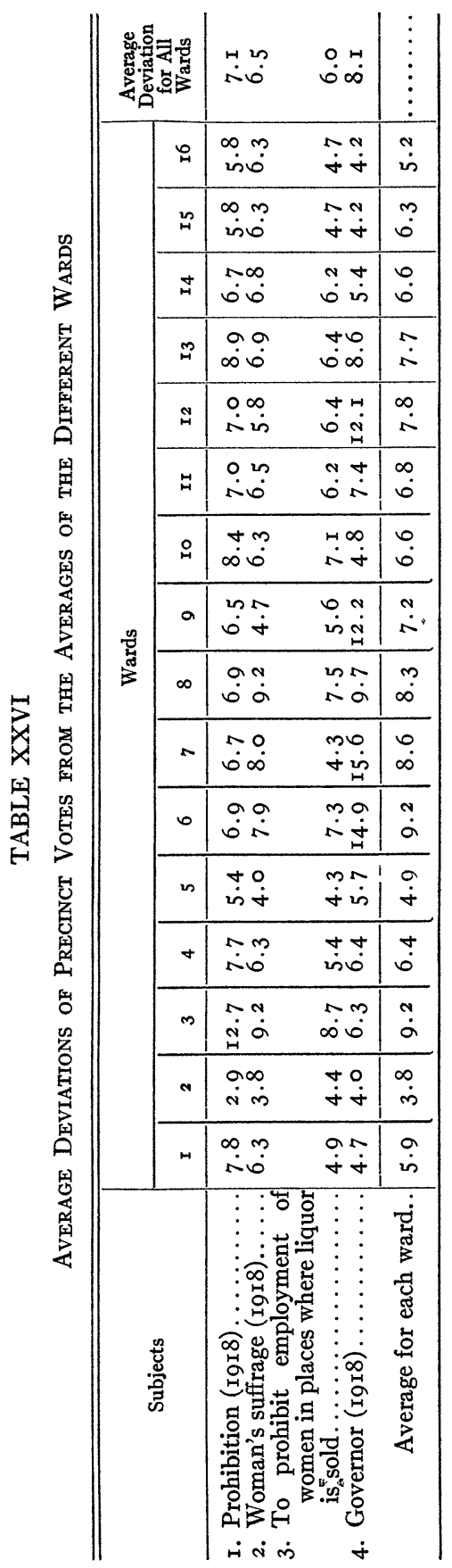

This content downloaded from 184.003.242.175 on March 01, 2018 22:41:59 PM All use subject to University of Chicago Press Terms and Conditions (http://www.journals.uchicago.edu/t-and-c). 
not equally artificial. Some show a much greater tendency toward homogeneity and coincidence with natural local groupings than others. In order to discover the comparative homogeneity of the different wards of Columbus I have made a study of the precinct variations of opinion for each ward. The method employed was as follows; the total percentage of affirmative votes in each ward on each of the four subjects indicated on Table XXVI, was taken as the basis. Then the percentage of affirmative votes on each subject for each precinct within the ward was compared with this, and the deviations averaged. Table XXVI gives the result of this tabulation for all the wards of the city.

A few interesting facts are revealed in this table. In the first place it is quite clear that there is considerable difference in the extent of solidarity in the various wards of the city. Ward 2 stands out conspicuously as distinctly the most homogeneous ward. With its average deviation on all subjects of but 3.8 , it stands in striking contrast to its neighboring Ward 3 , which has an average deviation of 9.2; and to Ward 6, which has an equally high average. In fact Ward 2 consistently shows greater homogeneity on all issues than any other ward in the city, with the two slight exceptions of Wards 5 and 7 , in item three, and in these particular cases the differences are extremely small.

The precinct deviations from the ward averages for Wards 2 and 3 are graphically represented in Graph III.

With the single exception of Precinct A, which stands at the northeast corner of the ward, there is extremely little geographical bunching of votes in Ward 2. Ward 3, on the other hand, shows the opposite tendency. Its precinct fluctuations vary from $\mathrm{I} 7$ to 62 per cent of the electors voting in favor of prohibition.

The superior homogeneity of Ward 2 is due to the fact that this ward is inhabitated almost exclusively by a single nationality, Germans. Ward 3, on the contrary, is composed of a number of different foreign groups in addition to a large American population.

A few conclusions may be drawn from this study of local opinion. First, the population of a city tends to segregate itself into locality groups possessing similar cultural and moral values; second, issues 
involving economic expenditure reveal more reflection and personal choice on the part of the voter than do issues pertaining to the mores; third, the ward is not a unit of opinion on any issue except where its boundaries happen to coincide with the natural cultural and ethnic groupings of the population.

Those interested in the rehabilitation of the city neighborhood must, if they are to succeed, take into consideration the dominant

\section{GRAPH III}

Comparative Homogeneity of Wards 2 and 3

As illustrated by precinct distribution of affirmative votes on the issue of prohibition, rgr8

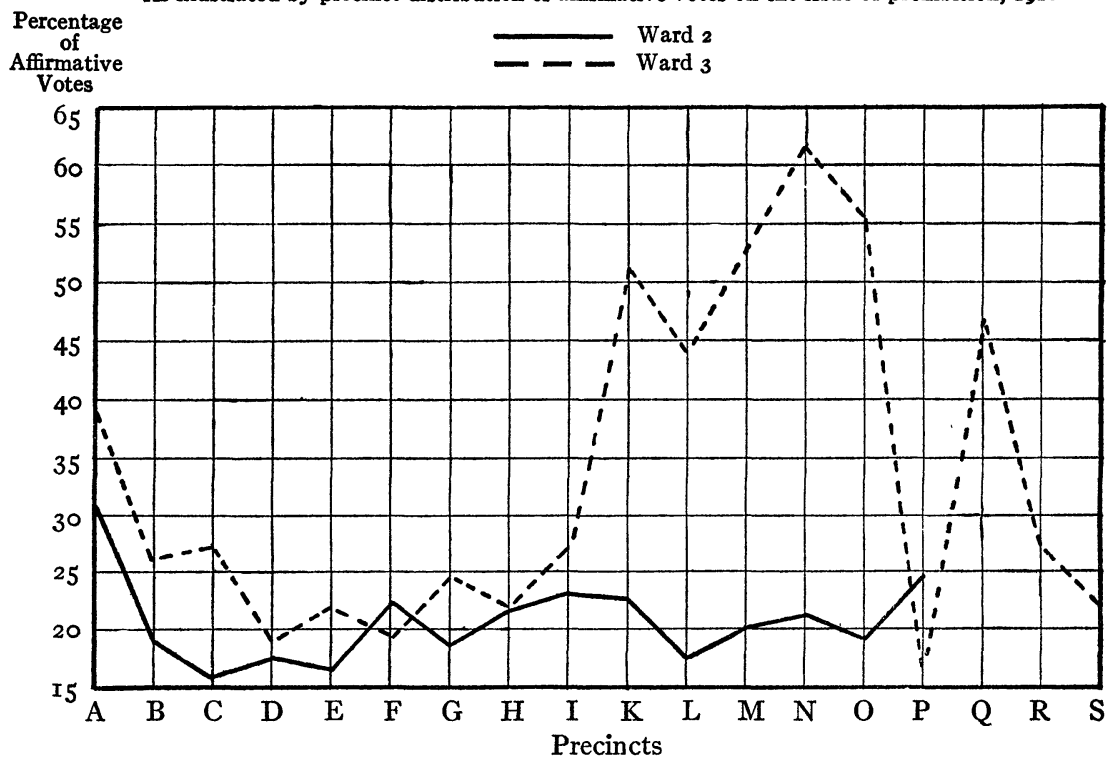

forces at work strengthening or disintegrating the locality groups. An efficient scheme of neighborhood reconstruction must take cognizance of the natural groupings of the population, and efforts must be made to stabilize such groupings as far as possible by establishing community safeguards against encroaching disturbing factors. On the other hand, efforts must be made to give to each neighborhood a physical unitary character sufficient to differentiate it from surrounding localities. This, of course, will involve a systematic scheme of city planning. The following quotation 
indicates that this subject is already receiving consideration from experts on city planning:

There is then a need today, from the standpoint of city planning, for a standard political area corresponding to the city neighborhood-or if one answers that there are no such things as city neighborhoods, then for the city neighborhoods that ought to exist. A large city should be divided into local or neighborhood governments, presumably elective, which should, under the city government, have charge of certain physical interests of the district. The desirability of having real city neighborhoods matching certain city planning needs-and, though meeting these, realizing also certain spiritual ends-neighborhoods defined and vitalized by the possession accordingly of certain governing powers, is enforced in many ways.

It is emphasized by the monotonous lack of local structural design and thus of efficient organic character in our outspread cities, looked at as wholes. It is emphasized by the struggling efforts of groups of persons in various localities, through local improvement clubs, to affect their local physical conditions by their joint efforts, and by the fact that, as things are, a great part of the people feel helpless or indifferent concerning these matters. It is emphasized by projects which have been made by architects and sociologists to design fit groupings for local institutions, business, cultural and social, with a view for the better performance of their proper functions and a better symbolizing of the idea of neighborhood solidarity.

It is emphasized by the zealous and in many places locally rooted social center movement, which has spread so widely during the last few years. It is emphasized by the desire of finest elements of many isolated nationality groups for broad and inclusive co-operation in their districts toward social welfare, and by the spreading notion that common folk should be mustered into the life of the community as they have not been heretofore. It is emphasized by the recognized need for moderating the excessive and wasteful mobility of city populations, by giving more meaning to locality and making neighborhoods more worthy of permanent residence. It is emphasized by the fact that certain local interests, touching both the physical functions and social aims of modem government, can be better understood and administered locally than by the long range machinery of a city government centering at city hall and covering perhaps scores or hundreds of square miles. It is emphasized by the historical fact that the finest architectural embodiments of human institutions and ideals have for the most part been wrought out by communities of limited size, as ancient Athens and the cathedral cities of Europe amply testify.

As to precisely what functions would lend themselves to efficient local management-possibly the design, construction, maintenance and adornment of local streets, the removal of household waste, the provision of some recreation factors, especially for the smallest children, the receipt of taxes, the registration 
of vital statistics, the development of an architectural scheme for a real neighborhood center-whether these are some of the functions which might be considered as appropriate for local management, is a question upon which I do not wish now to enter. Nor need we now discuss whether this primary governing area should comprise one square mile or ten, 10,000 people or 100,000. Cases would be decided according to circumstances. Just as local intelligence, pride, and initiative, however, are invaluable in smaller cities for the purpose of government, just as the value of these forces is indicated by that fear of losing them which leads many outside communities to resist annexation to larger communities-so, I believe, these forces will, when given fair opportunity, demonstrate their value and efficiency toward limited city neighborhood government on a well-considered plan. I believe that the proper scope and objects of city planning will be neither adequately conceived nor adequately achieved except through the application to the large city of some federal scheme which will bring to bear the potentialities of neighborhood political areas as such for their own higher physical organization. ${ }^{\mathrm{x}}$

However much we may idealize the values of the social solidarity of the traditional neighborhood and long for their return, the fact remains that our social order has changed profoundly from the organic life of the old hamlet or village societies. The seething movements of population show no signs of abating. Community life is ever growing more mobile and transitory. The demand for small homes or apartments, equipped with every possible built-in feature-if not completely furnished-is increasing. The modern family is loath to assume any responsibilities which may interfere with its freedom to move when opportunity or occasion arises. It is all a phase of the dynamic economic and social order in which we are now living. With the change undoubtedly we lose some of the values which went with solidarity, but, on the other hand, we gain much through the very looseness of the present social structure. Perhaps some of the neighborhood values may be restored by intelligent organization, but there seems to be little ground for belief that the dreams of the more extreme neighborhood promoters will ever be realized.

× George E. Hooker, "City Planning and Political Areas," National Municipal Review, VI (May, I9I7), 34I-42. 